Chapman University

Chapman University Digital Commons

ESI Working Papers

Economic Science Institute

2014

\title{
Single- and Double-Elimination All-Pay Tournaments
}

Cary Deck

ChapmanUniversity, deck@chapman.edu

Erik O. Kimbrough

Follow this and additional works at: http://digitalcommons.chapman.edu/esi_working_papers

Part of the Econometrics Commons, Economic Theory Commons, and the Other Economics Commons

\section{Recommended Citation}

Deck, C. and Kimbrough, E.O. (2014). Single- and double-elimination all-pay tournaments. ESI Working Paper 14-10. Retrieved from http://digitalcommons.chapman.edu/esi_working_papers/16

This Article is brought to you for free and open access by the Economic Science Institute at Chapman University Digital Commons. It has been accepted for inclusion in ESI Working Papers by an authorized administrator of Chapman University Digital Commons. For more information, please contactlaughtin@chapman.edu. 


\section{Single- and Double-Elimination All-Pay Tournaments}

\section{Comments}

Working Paper 14-10 


\title{
Single- and Double-Elimination All-Pay Tournaments*
}

\author{
Cary Deck $^{\dagger} \quad$ Erik O. Kimbrough ${ }^{\ddagger}$
}

June 24, 2014

\begin{abstract}
Tournaments consisting of iterative matches are a common mechanism for determining how to allocate a prize. While participants are focused on their own outcomes, tournament organizers often have objectives such as maximizing the total investment or effort by the participants over the course of the tournament. For this reason it is important for organizers to understand the behavioral as well as the theoretical properties of different tournament structures. Given that laboratory experiments have consistently found high levels of overbidding in contests, one might suspect that double-elimination tournaments would generate substantially more total investment than single-elimination tournaments despite the two types of tournaments generating theoretically equivalent expected aggregate investment. This paper reports a set of laboratory experiments designed to test this comparison. The results indicate that aggregate investment is similar between the two tournaments. While observed behavior in the single-elimination tournament is quite similar to theoretical predictions, behavior in the double-elimination tournament appears to be impacted by an implicit, self-imposed budget constraint.
\end{abstract}

JEL classifications: $C 7, C 9, D 4, D 7$

Keywords: elimination tournaments, all-pay auctions, experiments

\footnotetext{
${ }^{*}$ The authors thank the Visiting Scholars Program at the Sam M. Walton College of Business at the University of Arkansas for generous financial support. We would like to thank Nidhi Dahiya for excellent research assistance and Dave Freeman for helpful discussions. Figures were created using the open-source statistical software R.

${ }^{\dagger}$ Department of Economics, University of Arkansas, Fayetteville, Arkansas, and Economic Science Institute, Chapman University, Orange, California, e-mail: cdeck@walton.uark.edu

¥Corresponding Author: Department of Economics, Simon Fraser University, 8888 University Drive, Burnaby, BC V5A 1S6, Canada, e-mail: ekimbrou@sfu.ca
} 


\section{Introduction}

Multi-stage elimination tournaments are common. One prominent example that has received much attention in the economics literature is labor promotions in which employees compete based on performance to move up the corporate ladder (Lazear and Rosen, 1981; Altmann et al., 2012). Another place where tournaments are common is in competitions for start-up funding where entrepreneurs pitch business plans for access to a pool of funding. As an example, the 43North Competition (see http://www.43north.org/) is awarding \$5 million dollars in 2014 through a three round competition to foster economic growth and development in Buffalo, New York. Elimination tournaments are also prevalent in sports.

In all of the settings described above, the organizer of the tournament desires for the contestants to put forth maximum effort. This has led practitioners and researchers to consider several aspects of tournament structure. The 43North competition does not award the full prize money to a single winner, but instead spreads these funds across contestants in a graduated fashion. Theoretically, the effectiveness of splitting the prize depends on a wide variety of factors including the institutional details of how effort affects the chance of winning as well as characteristics of the contestants such as risk attitude (see Sisak, 2009, for a survey). Recognizing that contestants have heterogeneous ability, tournaments can be seeded. However, an increase in heterogeneity often leads to lower effort because of a discouragement effect. ${ }^{1}$ This has lead researchers to investigate optimal seeding (Groh et al., 2012) and the potential for pre-contest shirking to manipulate seeding (Dagaev and Sonin, 2013). ${ }^{2}$

Despite the interest in encouraging effort, tournaments are typically single-elimination, although some collegiate sports such as baseball and softball employ a double-elimination format. $^{3}$ Theoretically, single- and double-elimination tournaments where each match involves two players should generate the same level of total effort, when each match is resolved as an all-pay auction (see discussion in the next section). However, one of the most robust findings

\footnotetext{
${ }^{1}$ See Baye et al. (1993), Baik (1994), and Stein (2002) for theoretical discussions and Anderson and Freeborn (2010) and Kimbrough et al. (2014) for experimental support.

"See the recent allegations of "tanking" in the NBA, in which teams deliberately lose to increase their seeding in the draft lottery. The Chinese badminton team was also accused of manipulation at the 2012 Summer Olympics.

${ }^{3}$ Professional sports leagues such as the NBA, NHL, and MLB employ single elimination tournament, where each the winner of each match is based on the best-of-seven games.
} 
from the literature on contest experiments is that people tend to overbid (i.e. exert more than the equilibrium level of effort). In particular, expenditures are often higher than the Nash equilibrium predictions in magnitudes ranging from $50 \%$ to $200 \%$. This over-competition is reduced with repetition, but it does not disappear (Davis and Reilly, 1998; Potters et al., 1998; Sheremeta, 2013). This behavioral pattern would suggest that a double-elimination structure may be more effective in generating tournament-wide effort than a single elimination structure since it provides more opportunities for people to overbid and those who advance in the tournament are more likely to be overbidders. In this paper, we experimentally compare the behavioral performance of theoretically equivalent single- and double-elimination tournaments.

While there are now a large number of experiments investigating behavior in contests (see Dechenaux et al., 2012), there are relatively few laboratory studies of multi-round tournaments. Parco et al. (2005); Amaldoss and Rapoport (2009) and Sheremeta (2010a,b) all study variants of a two-stage single-elimination contest with a lottery contest success function, and they find evidence of overbidding regardless of whether players face budget constraints over the course of the tournament or effort in one stage has a spillover to another stage. Altmann et al. (2012) study multi-stage single-elimination rank-order tournaments in a labor market context and find similar evidence of overbidding. Amegashie et al. (2007) examine two-stage single-elimination tournaments with all-pay contests in which bidders face an explicit budget constraint for the tournament. In their set-up where everyone competes with everyone at each round, they find evidence that bidders "burn out" their entire budget in the first stage, consistent with the coalition proof Nash equilibrium.

We find that profits are negative on average (inconsistent with the point predictions of the theory), but we find little evidence that total profits differ across treatments (consistent with the comparative statics of the theory). Thus we turn our analysis to bidding behavior to explore the patterns of choices that generate these observations. For both tournaments, in equilibrium non-negligible effort is only invested in a second round between two contestants that each won their first match. We find that bids are much higher in the second round than the first round of the single-elimination tournaments, which is consistent with the comparative statics of the theory. However, in the double-elimination tournaments most bidding occurs in the fourth and 
fifth rounds. One plausible explanation for this pattern is that contestants self-impose a budget constraint for the tournament.

Our results suggest that the commonly observed phenomenon of overbidding in a single contest may not carry over to more complicated tournament settings, meaning organizers would not necessarily increase total investment by moving from single- to double-elimination tournaments. If each of the contests is costly then single-elimination is likely preferred, but if there are other benefits each round then a double elimination tournament may be preferred. Perhaps this is why sports, where ticket and concession sales can be sizable, provide the most readily available examples of double-elimination tournaments in practice.

The remainder of the paper unfolds as follows. In section 2 we discuss the theoretical predictions for our setting. Section 3 describes the experimental design and our hypotheses. Section 4 reports our findings; section 5 discusses the interpretation of our findings, and section 6 concludes.

\section{Theoretical Considerations}

In this section we describe the format of our single- and double-elimination tournaments and characterize equilibrium bidding strategies. We consider four-player tournaments that yield a

single winner who claims a prize $V \geq 0$. A tournament is composed of multiple rounds, each of which is composed of one or more matches. In a match, two players bid in a first price all-pay auction (Moulin, 1986); the high bidder wins the match and ties are broken randomly (with one exception discussed in detail below).

Baye et al. (1996) characterize the mixed-strategy Nash equilibrium (MSNE) for the general one-shot first price all-pay auction. Of relevance here, they show that if both players value winning the match at $v$ then the unique MSNE is for both players to bid randomly from the uniform distribution over the interval $[0, v]$. Further, the expected payoff to each bidder in equilibrium is 0 .

How players are assigned to matches in the tournament and how the ultimate winner is determined depends on the tournament type. Let $b_{i, t}$ be the bid of player $i$ in round $t$, and let $\tau_{i}$ 
be the set of all rounds in which player $i$ submitted a bid. Regardless of whether the tournament is single- or double-elimination, the payoff to bidder $i$ is:

$$
\pi_{i}=\left\{\begin{array}{lr}
V-\sum_{t \in \tau_{i}} b_{i, t} & \text { if } i \text { wins the tournament } \\
0-\sum_{t \in \tau_{i}} b_{i, t} & \text { otherwise }
\end{array}\right.
$$

We now consider each tournament structure in turn.

\subsection{Single-elimination Tournaments}

In the single-elimination tournament, there are two rounds and a player is eliminated after losing once. In the first round, bidders are randomly paired into two matches. The losers of the two first-round matches are eliminated. The winners of the two first-round matches advance to the second round where they face each other. The loser of the second-round match is eliminated. The winner of the second-round match wins the tournament and receives the prize. Figure 1 displays the single-elimination tournament graphically.

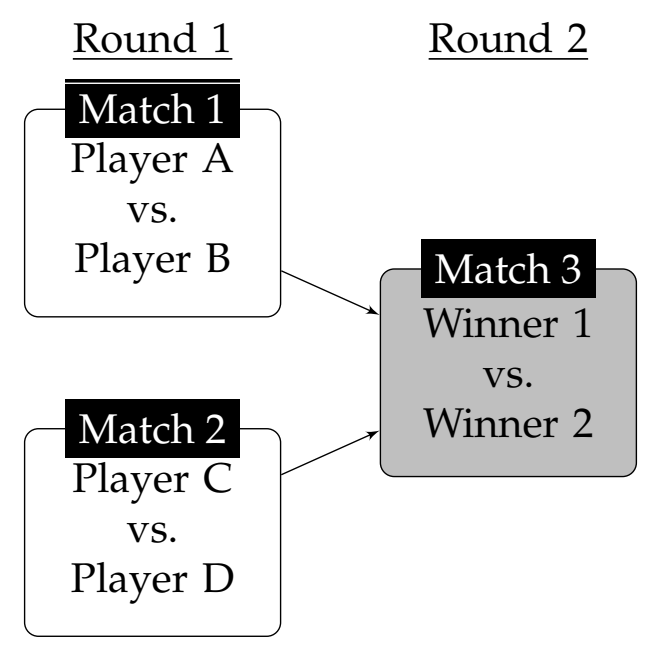

Figure 1: Single-elimination Tournament. Solid arrows indicate the path taken by match winners between rounds. Grayscale node indicates the match in which bidders should submit positive bids.

Given the sequential nature of the tournament, the appropriate solution concept is that of sub-game perfection. In round 2, the bidders compete in an all-pay auction for a prize of $V$. From (Baye et al., 1996), the expected profit to each bidder is 0. Using backwards induction, 
winning in round 1 generates an expected prize of 0 , and so does losing. Hence, the optimal bid in round 1 is 0 . Thus, the subgame perfect equilibrium (SPE) bid function is:

$$
b_{i, t}\left\{\begin{array}{cc}
=0 & \text { if } t=1 \\
\sim \mathrm{U}[0, V] & \text { if } t=2
\end{array}\right.
$$

Given this, the expected total bid in the first round is 0 and the expected total bid in the single elimination tournament is $V$.

\subsection{Double-elimination Tournaments}

In the double-elimination tournament, there are either four or five rounds, and a player is not eliminated until he or she has lost twice. In the first round, bidders are randomly paired into two matches. The two winners from the first-round advance to face each other in the second round in a "winner-winner" match. Similarly, the two losers in the first-round face each other in a "loser-loser" match in round 2. The loser of the "loser-loser" match is eliminated, and the winner of the "winner-winner" match gets a "bye" in round 3, while the two bidders who have each won and lost a match compete in round 3. The loser in round 3 is eliminated, and the winner advances to round 4 . In round 4 , the winner of round 3 competes with the bidder who had a bye in round 3. In round 4 only, ties are broken in favor of the bidder with a round 3 bye. If the player with the bye in round 3 wins round 4 , then this player is the winner of the tournament and claims the prize, while the other player is eliminated. If the bidder who has a bye in round 3 is the loser in round 4 , then the two bidders who competed in round 4 compete again in round 5. If there is a round 5, the winner of that round is the winner of the tournament and claims the prize while the loser is eliminated. Figure 2 displays the double-elimination tournament graphically.

As in the single-elimination case, we can identify the SPE of this game by backward induction. Consider the optimal strategies of bidders in round 5. As with round 2 of the singleelimination tournament, this is an all-pay auction for a prize $V$. Each bidder will randomize over the interval $[0, V]$ and each bidder has an expected profit of 0 . In round 4 , the bidder who 


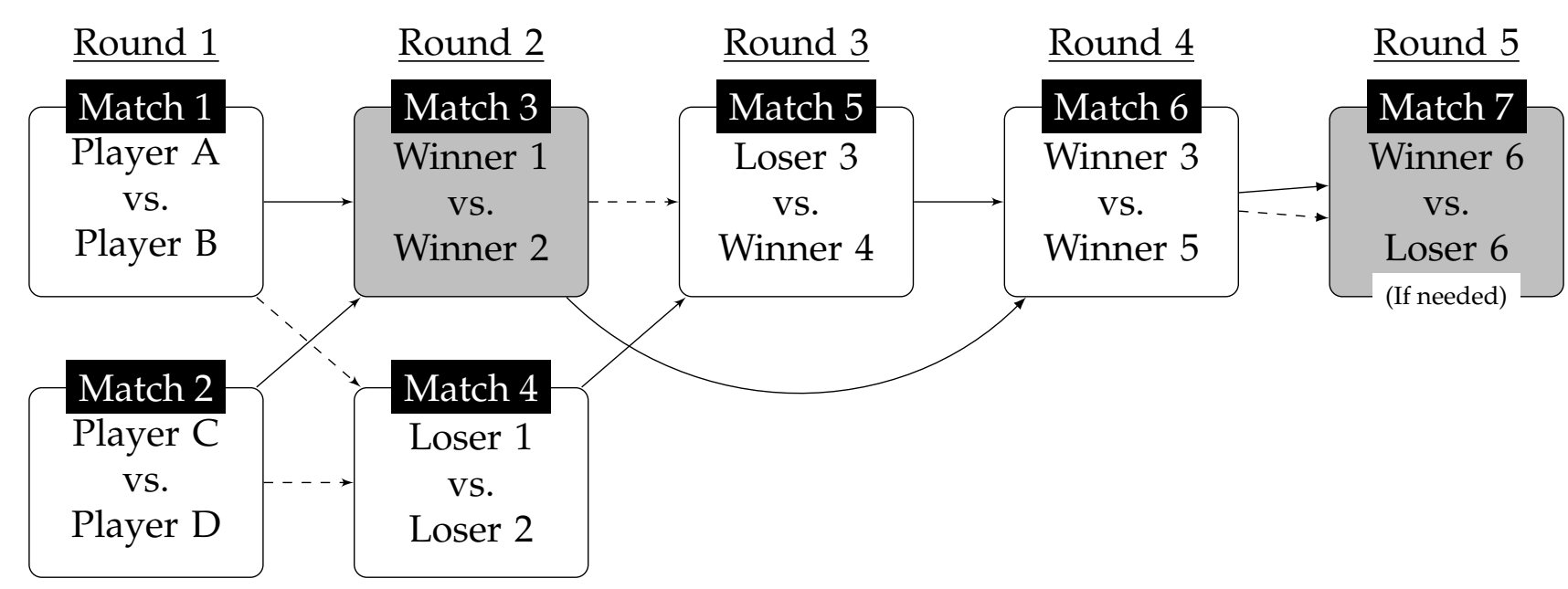

Figure 2: Double-elimination Tournament. Arrows indicate the path taken by match winners (solid arrows) and losers (dashed arrows) between rounds. Note that winners in Match 3 get a "bye" in Round 3. Grayscale nodes indicate the matches in which bidders should submit positive bids.

did not have a bye in round 3 will be eliminated and earn 0 with a loss and expects to earn 0 with a win, since this will cause the tournament to continue to round 5 . Therefore, this bidder will optimally bid 0 . The bidder who had the bye in round 3 will optimally bid the smallest allowable amount that results in a certain win in round 4 . Given the tie breaking rule in this round, the optimal bid is 0 , resulting in a profit of $V .4$ In round 3, the loser is eliminated and the winner expects to be eliminated in round 4 . Thus, regardless of the outcome, a bidder in round 3 expects to earn 0 and thus should bid 0 . In round 2, there are two concurrent matches. In the "loser-loser" match the loser is eliminated and earns 0 and the winner will proceed to round 3 where she expects to earn 0 . Thus, both bidders in the "loser-loser" match should bid 0 . In the "winner-winner" match the loser will proceed to round 3 and expects to earn 0 while the winner will receive the bye and expects to win the tournament in round 4 and earn $V$. Hence, as in round 2 of the single-elimination tournament, the two bidders are in an all-pay auction for a prize of $V$ and will bid according to the model of (Baye et al., 1996) and earn an expected profit of 0 . Therefore, in the first round regardless of the outcome a bidder expects to earn 0 and thus should bid 0 . The SPE is formalized by:

\footnotetext{
${ }^{4}$ If ties were randomly broken in round 4 , then the bidder with the bye in round 3 would bid an arbitrarily small amount, which in the limit approaches 0 and results in an expected profit of $V$.
} 


$$
b_{i, t}\left\{\begin{array}{cc}
\sim \mathrm{U}[0, V] & \text { if } t=2 \text { and } i \text { won in round } 1 \text { or } t=5 \\
=0 & \text { otherwise }
\end{array}\right.
$$

The total bid is 0 in rounds 1,3 and 4 . Although total bids in round 5 are expected to sum to $V$, this round is not reached in equilibrium. Therefore, the total expected bid in the tournament is equal to the total expected bid in round 2, $V$, all of which comes from the "winner-winner" match. The total expected bid is the same as in the single-elimination tournament. Further, both tournaments should not generate any positive bids in the first round and the only match that should yield positive bids is the second round match between the two first round winners.

\section{Experimental Design}

We employed a within-subjects experimental design to explore bidding behavior in single- and double-elimination tournaments. Subjects competed in a series of tournaments with a prize worth \$10. After entering the laboratory, subjects were seated at private stations and read onscreen instructions explaining the structure of an all-pay auction (see Appendix A). Then they participated in seven practice matches that did not affect their payment. These matches are the same as the final round of a single- or double-elimination tournament. The practice matches were designed to help subjects learn the strategic properties of the all-pay auction and familiarize them with the computer interface. At the conclusion of each practice match, the winner was revealed, and participants learned their own (hypothetical) payoff. During the practice matches, an experimenter answered questions about the rules and made sure that participants understood how their actions and those of their opponent determined their payoffs.

After the practice matches, subjects read a second set of instructions explaining either singleor double-elimination tournaments, depending on the session. In half of our sessions, subjects competed in single-elimination tournaments after the practice matches and in the other half, they competed in double-elimination tournaments after the practice matches. This design feature allows us to reduce noise via within-subject treatment comparisons while also identifying and controlling the effects of tournament experience on behavior. 
At the conclusion of the treatment instructions, subjects then competed in 10 tournaments. Each tournament had 4 bidders, drawn at random from a matching group of 8 , who were each randomly assigned a color to identify them (this color changed at the beginning of each tournament to preserve anonymity). After 10 tournaments, subjects read a third set of instructions explaining the details of the other type of tournament and then participated in 10 tournaments of the new type with the same matching group of 8 . Finally, for the last three tournaments we allowed subjects to vote for their preferred tournament type. A simple majority of the matching group (with ties broken randomly) determined the tournament type, and the contest proceeded accordingly. The voting treatment allowed us to 1) observe subjects' preferences for a particular tournament type after they had experience with both options, 2) test whether their choices in the opt-in setting were consistent with those when the tournament format was exogenously imposed, and 3) observe whether past experience influenced the choice of tournament format. At no point were subjects informed that there would be additional phases of the experiment. Figure 3 displays the sequence of tournaments in each session.

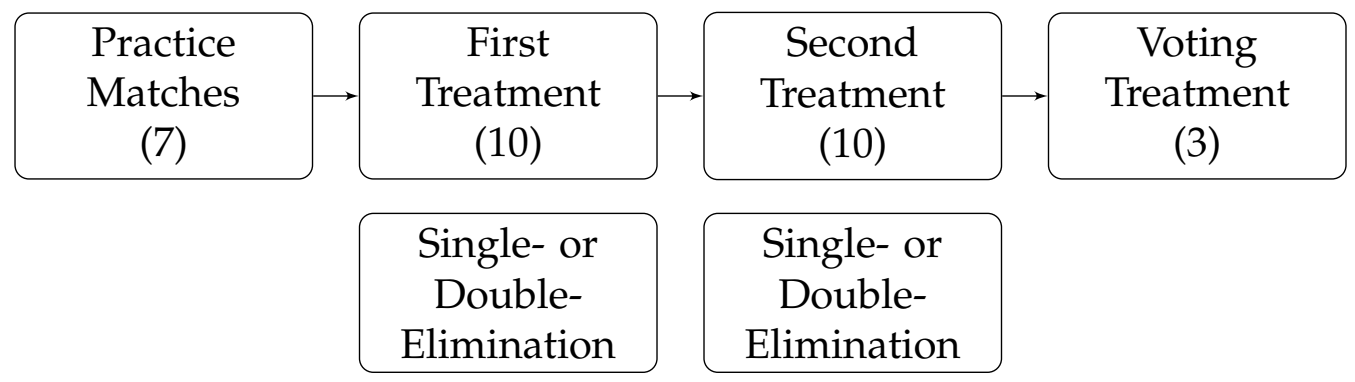

Figure 3: Flow diagram of the experimental design.

During each tournament, subjects received feedback on players' bids, the winner of each match, and own earnings. Figure 4 displays a screenshot from a subject's point of view in the double-elimination treatment. The tournament bracket updated in each round to reflect the winners and losers of the previous matches; the winner and loser in each match were identified explicitly by the appearance of $\mathrm{W}$ and $\mathrm{L}$ symbols and implicitly through the reconfiguration of the tournament bracket. The visual presentation of the tournament and associated outcomes was designed to facilitate subject understanding.

Subjects began the experiment with a \$20 endowment (which included a \$5 payment for 


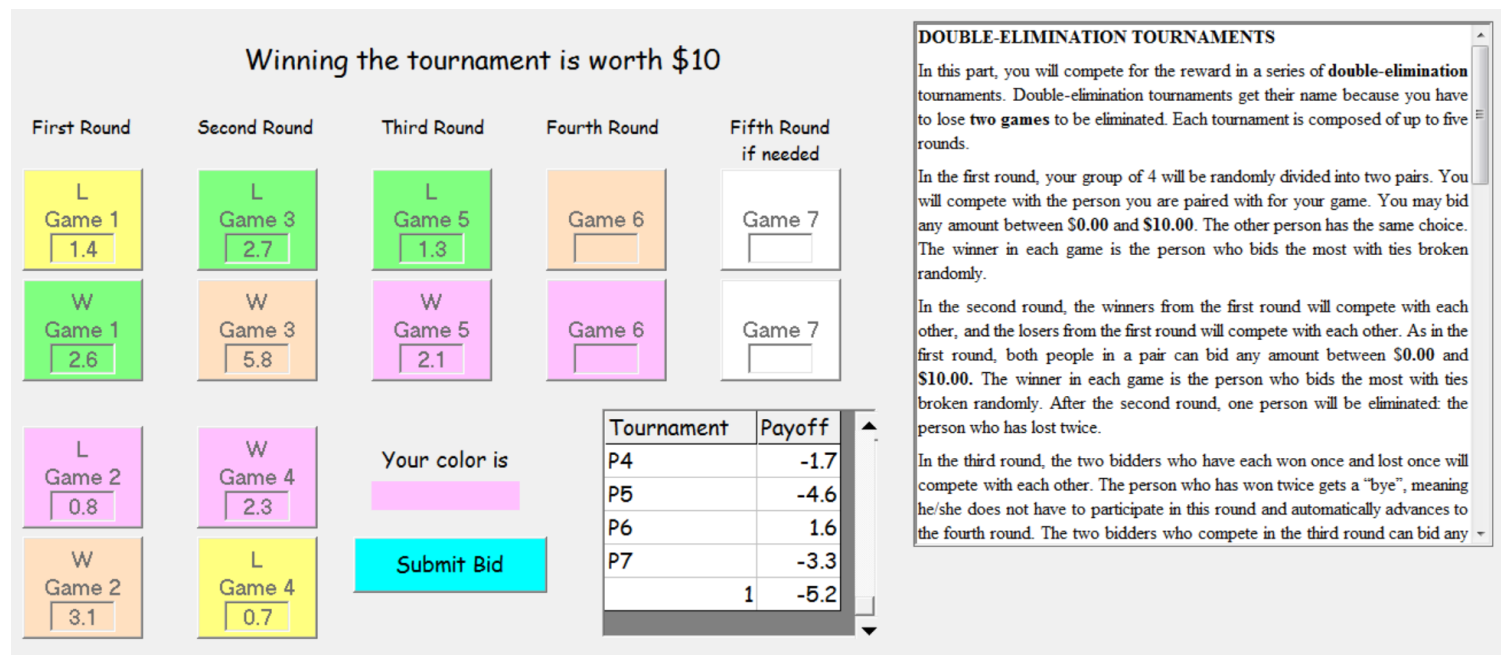

Figure 4: Screenshot of the experimental interface.

arriving on time). In each round, subjects were able to submit bids between $\$ 0$ and $\$ 10$ in increments of $\$ 0.10$, and all bidders had to pay the sum of all their bids in each tournament. At the conclusion of the session, each participant was paid based on their decisions and the resulting outcome from one randomly chosen tournament. The random selection of a single tournament reduces the size of the endowment that must be given to each subject in order to reduce the chance of bankruptcy (which would result in a loss of control by the experimenter). If earnings are positive in the randomly selected tournament, these were added to the $\$ 20$, and if earnings were negative, they were subtracted. Because subjects are expected to place positive bids in at most two rounds, the endowment was set equal to twice the $\$ 10$ prize to further minimize the chance of bankruptcy. We observed only 6 instances out of 1840 salient tournaments in which an individual's tournament earnings would have led to bankruptcy, and none of these were drawn for payment.

We ran ten total experimental sessions (five in each ordering, i.e. single-double or doublesingle), and each session contained 8 subjects. Our subjects (66\% male) were recruited from the University of Arkansas Behavioral Business Research Lab's online recruiter system, and we collected no other demographic information. All participants pre-registered with the lab and were invited by email. Average payment per subject was $\$ 19.52$. 


\subsection{Hypotheses}

The experiment is designed to test whether the strategic equivalence of these two tournament formats established in Section 2 also generates behavioral equivalence. This can be stated as three specific hypotheses:

Theoretical Hypothesis 1: Average payoffs will be equal to 0 for each tournament type.

Theoretical Hypothesis 2: Bidding in both tournament types will follow the SPE; that is, players will submit bids of 0 in every match except the "winner-winner" match of round 2 and round 5 of the double-elimination tournament, should it arise, in which case bids will be uniformly distributed on the interval $[0, V]$.

Theoretical Hypothesis 3: Bidders will be indifferent as to which tournament type is used.

Given what has been observed in previous laboratory contests (Dechenaux et al., 2012; Sheremeta, 2013), a priori we anticipated that we would observe overbidding in both treatments. If this wellestablished pattern holds, this generates a set of alternative hypotheses. In particular, since there are more opportunities to overbid in double-elimination tournaments and overbidders are more likely to advance, we would expect lower payoffs in the double-elimination tournaments.

Behavioral Hypothesis 1: Average payoffs will be lower in the double-elimination tournaments than in the single-elimination tournaments.

Behavioral Hypothesis 2: We will observe overbidding relative to the SPE in both tournament types, but bids across tournament types will be indistinguishable in strategically equivalent matches.

Behavioral Hypothesis 3: Bidders will prefer single-elimination tournaments in order to avoid the increased costs of double-elimination tournaments. 


\section{Experimental Results}

The experimental results are presented as a series of findings in separate subsections. We begin by analyzing data on outcomes, and we find mixed evidence that our data is consistent with the theory. Specifically, while we find that profits are negative on average (inconsistent with the point predictions of the theory and consistent with prior evidence from all-pay auction experiments), we find little evidence that total profits differ across treatments (consistent with the comparative statics of the theory). In the second subsection we analyze bidding behavior in individual matches. We find that bids are reflective of the theoretical predictions in single-elimination tournaments even if they do not strictly coincide statistically. However, in the double-elimination tournaments most bidding occurs in the final two rounds of the tournament, contrary to the theoretical predictions. In the final subsection, we examine subject preferences over tournaments. Empirically, they prefer single-elimination, and bidding behavior in endogenously selected tournaments is similar to that in the exogenously selected tournaments.

\subsection{Profits}

Figure 5 shows histograms of individual profits by treatment and reveals that profits are skewed negative. On average, a bidder can expect to lose 78 cents/tournament in the single elimination treatment and 123 cents/tournament in the double-elimination treatment, which given that there are 4 bidders per tournament, indicates that $131 \%$ of the prize value is dissipated on average in the single-elimination treatment and $149 \%$ of the prize value is dissipated in the doubleelimination treatment. Averaging over all periods and individuals in each session, we reject the null hypothesis that average profits are equal to zero in both the single- and double-elimination treatments (two-sided Wilcoxon signed-rank tests, $\mathrm{V}_{10}=7, p$-value $=0.037$ and $\mathrm{V}_{10}=0, p$-value $=0.002$, respectively), and the results are qualitatively similar if we restrict attention to the final five periods of each treatment.

Figure 6 shows time series of average profits earned by bidders in each session of each treatment. Since we employ a within-subject experimental design, we report paired hypothesis tests to compare profit across treatments. In 7 out of 10 sessions, average profits are lower in the 
(a) Single

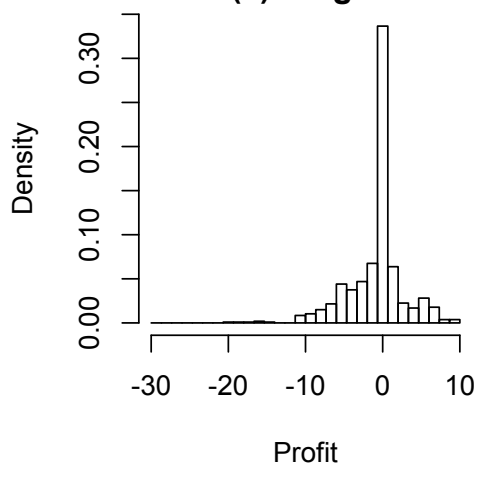

(b) Double

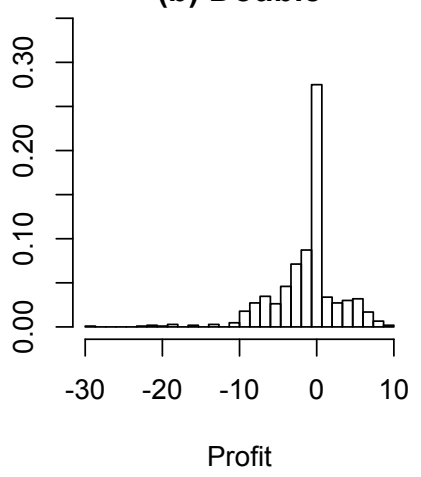

Figure 5: Histograms of individual profit by treatment.

double-elimination tournament, but despite the difference in means, a Wilcoxon signed-rank test cannot reject the null hypothesis that treatment differences are equal to zero $\left(V_{10}=42, p\right.$ value $=0.16$, two-sided test). Indeed, the figure suggests that experience may play an important role as profits tend to be lowest in the early tournaments of whichever treatment was introduced first, though this feature of the data is more pronounced when subjects first experience doubleelimination and then single-elimination tournaments. ${ }^{5}$ When we compare only the final five periods of each treatment, the results give even less indication of differences across treatments $\left(\mathrm{V}_{10}=31, p\right.$-value $\left.=0.77\right)$. Regression analysis on individual profits qualitatively supports these conclusions (see Appendix B).

Finding 1: While profits are below the equilibrium level in both treatments, we find little evidence of differences between the treatments. Therefore we reject both Theoretical Hypothesis 1 and Behavioral Hypothesis 1, but note that the equivalence between treatments is consistent with the comparative statics of the theory while the level of profits is consistent with the behavioral predictions.

\subsection{Bidding Behavior}

Bidding data allows us to directly test whether subjects follow the equilibrium strategies in each tournament format. Figure 7 shows histograms of bids in each round of the single-elimination treatment. While theory predicts that all bidders will bid $\$ 0$ in round 1 , we observe many pos-

\footnotetext{
${ }^{5}$ If we restrict attention to the first period of bidding, average losses per bidder are 133 cents in the singleelimination tournament and 387 cents in the double-elimination tournament, and a Wilcoxon signed-rank test weakly rejects the null hypothesis of zero differences $\left(\mathrm{V}_{10}=45, p\right.$-value $=0.08$, two-sided test).
} 


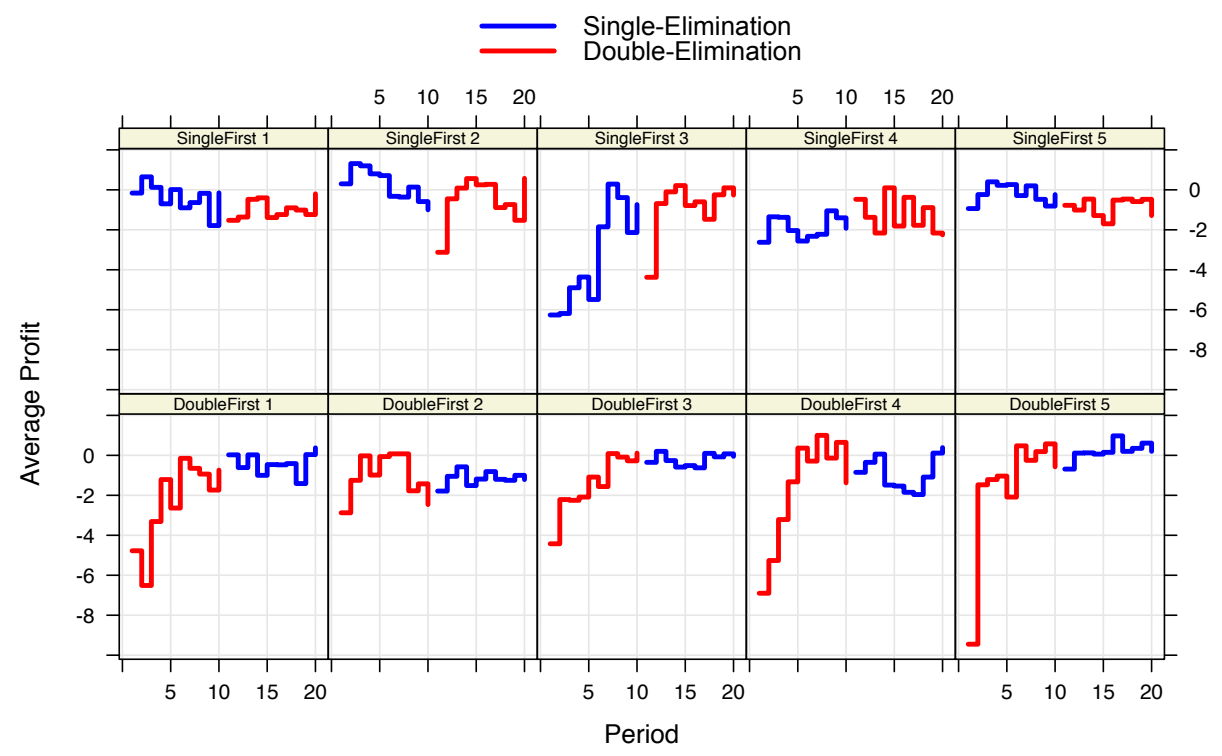

Figure 6: Time series of profits by session and treatment.

itive bids and the mean bid is $\$ 1.17 .6$ In round 2, theory predicts that bids will be uniformly distributed on the interval $[\$ 0, \$ 10]$. A Kolmogorov-Smirnov test rejects the null hypothesis that the empirical distribution of bids matches the theoretical distribution $(\mathrm{D}=0.15, p$-value $<$ 0.001, two-sided test). We treat each bid as an independent observation as this is justified under the null hypothesis that bidders follow the SPE strategy; in equilibrium, individuals' bids are drawn iid from the uniform distribution. Despite behavior not strictly following the theoretical predictions, behavior in Figure 7 is nominally in line with the model. In fact, if attention is restricted to the last half of the tournaments in the single-elimination treatment, round 2 bids are insignificantly different from the uniform distribution ( $p$-value $=0.29$ ).

Figure 8 shows histograms of bids in each round of the double-elimination treatment. Here theory predicts that bids will equal zero in rounds 1, 3 and 4 as well as in the "loser-loser" match of round 2. The "winner-winner" matches in round 2 and round 5 (should a pair reach it) are predicted to yield uniformly distributed bids on the interval [\$0, \$10]. Except for Round 4, bids are greater than $\$ 0$ where $\$ 0$ is predicted, but not dramatically so (but because the data are censored below, standard non-parametric tests reject the hypothesis sharply). In Round 4,

\footnotetext{
${ }^{6}$ Since 0 is a boundary prediction and deviations can only be in one direction, rejection of the null hypothesis is virtually guaranteed when we observe a mass of positive bids; hence we do not report statistical tests of this hypothesis.
} 

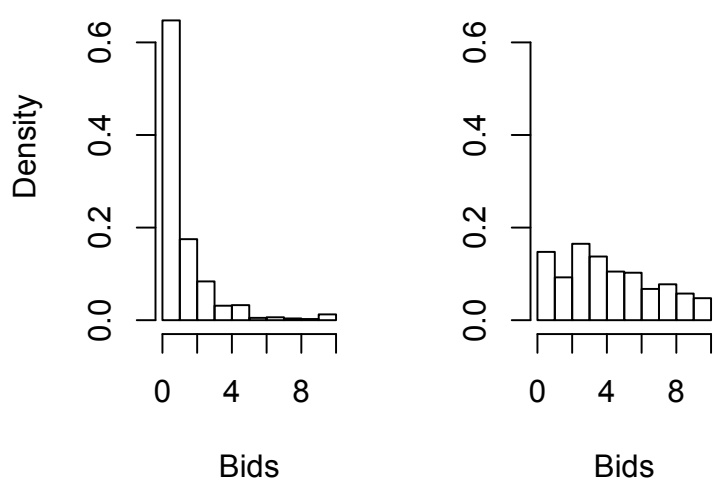

Figure 7: Histograms of bidding behavior in each round of the single-elimination treatment.

bids are very different from $\$ 0$, as subjects compete heavily. We also reject the null hypothesis that bids are distributed uniformly in the "winner-winner" matches in round 2 (KS tests, D = $0.68, p$-value $<0.001$, two-sided test). In fact, behavior in the winner-winner match is similar to other behavior in early rounds. In round 5, behavior also differs dramatically from the predicted uniform distribution ( $\mathrm{KS}$ test, $\mathrm{D}=0.37, p$-value $<0.001$, two-sided test); bidders rarely place bids over $\frac{V}{2}$. Further, we can reject the null hypothesis that bids in the winner-winner match of round 2 and bids in round 5 are drawn from the same distribution (KS test, D $=0.61, p$-value $<$ 0.001, two-sided test).
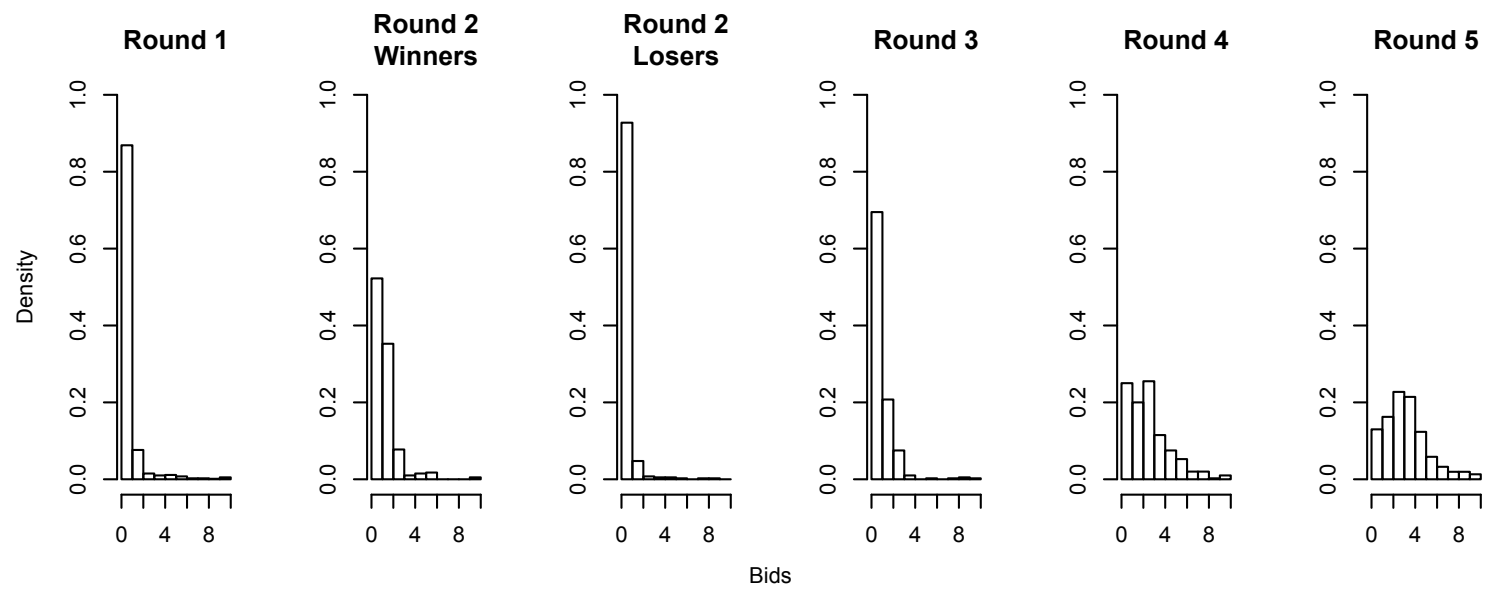

Figure 8: Histograms of bidding behavior in each round of the double-elimination treatment.

Next we compare bids in strategically equivalent contests across treatments. For reference, Table 1 displays mean and median bids by treatment and round. We first compare round 2 of the single-elimination tournaments to the round 2 winner-winner and round 5 matches 
in double-elimination tournaments. Either comparing separately by matches or pooling the double-elimination matches, two-sided KS tests reject the null hypothesis that bids are drawn from the same distribution (all $p$-values $<0.01$ ). Comparing round 1 of the single-elimination tournament to the strategically equivalent matches in the double-elimination tournament, either individually or collectively, two-sided KS tests again reject the null hypothesis that bids are drawn from the same distribution (all $p$-values $<0.01$ ). This is true despite the overwhelming visual similarity between bid distributions in some of the matches. ${ }^{7}$ These results are confirmed with random-effects Tobit regression analysis reported in Appendix B.

\begin{tabular}{|c|c|c|c|c|c|c|c|c|}
\hline & \multicolumn{2}{|c|}{ Single-Elimination } & \multicolumn{6}{|c|}{ Double-Elimination } \\
\hline & $\mathrm{Rd} 1$ & $\mathrm{Rd} 2$ & $\mathrm{Rd} 1$ & W.Rd2 & L.Rd2 & $\mathrm{Rd} 3$ & $\mathrm{Rd} 4$ & Rd5 \\
\hline Mean & 1.17 & 4.23 & 0.59 & 1.22 & 0.29 & 0.93 & 2.58 & 3.31 \\
\hline Median & {$[0.5]$} & [4] & {$[0.2]$} & [1] & [0] & {$[0.6]$} & [2.25] & [3] \\
\hline Std. Dev. & (1.73) & $(2.76)$ & $(1.22)$ & $(1.25)$ & $(0.84)$ & (1.15) & $(1.92)$ & (1.98) \\
\hline
\end{tabular}

$\mathrm{W}=$ winner-winner match, $\mathrm{L}=$ loser-loser match, $\mathrm{O}=$ overall average.

Table 1: Summary statistics of bids by round and treatment.

Finding 2: In single-elimination tournaments, behavior is qualitatively similar to the theoretical predictions, providing support for Theoretical Hypothesis 2. However, in double-elimination tournaments, we reject both Theoretical and Behavioral Hypothesis 2. Subjects in these underbid in the winner-winner and round 5 matches and over-bid in round 4.

\subsection{Voting Treatments}

In total $68 \%$ of individual votes went to the single-elimination tournament. Since each person voted three times, we classify each person as preferring the tournament structure they voted for a majority of the time. $69 \%$ of subjects are classified as preferring the single elimination

\footnotetext{
${ }^{7}$ If we restrict attention to the final 5 tournaments our results are qualitatively unchanged except that comparing round 1 bids in the single-elimination tournaments to the pooled bids from all strategically equivalent matches in the double-elimination tournament are not significantly different ( $p$-value $=0.52$ ). We also find similar results if we only look at the final tournament.
} 
tournament; a two-sided binomial test indicates this is significantly different from chance ( $p$ value $<0.01)^{8}$

Looking at the data more closely suggests that votes were influenced by treatment order. In particular, individuals were significantly more likely to vote for double-elimination tournaments when the voting treatment came immediately after the double-elimination treatment. Averaging over the three periods of the voting treatment for each subject, we find mean votes for the double-elimination treatment of $43 \%$ and $22 \%$, and a Wilcoxon rank-sum test rejects the null hypothesis that treatment order has no effect on the probability of voting for the double-elimination tournament ( $p$-value $=0.013$, two-sided test).

(a) Single

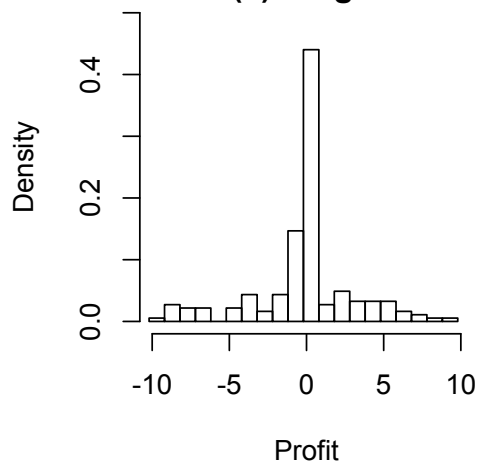

(b) Double

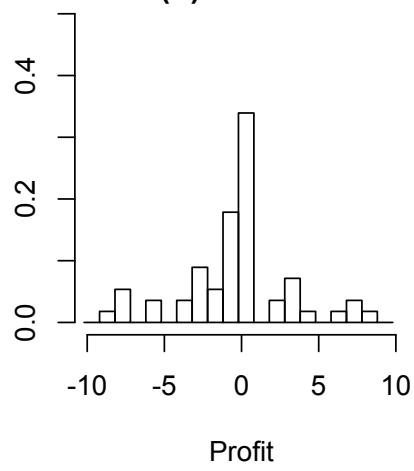

Figure 9: Histograms of individual profit by tournament format in the voting treatment.

We now examine behavior in tournaments during the voting phase of the experiment, recognizing the inherent endogeneity in the behavior. Figure 9 displays histograms of individual profits by tournament format in the voting treatment. As before, profits skew slightly negative, but the bulk of the observations are near 0 in both formats. Since not every individual or session was observed in every tournament type during the voting treatment, we employ GLS regressions to analyze profits. We regress individual profits on an intercept, a time trend variable within a treatment (Period), a dummy to control for the treatment order Order), and double-elimination treatment dummy (Double-Elim) and whether a subject voted to be in a double-elimination tournament (Voted Double-Elim). We include random effects for each subject and cluster standard errors at the session level.

\footnotetext{
${ }^{8}$ If we classify sessions rather than individuals, a two-sided Wilcoxon signed-rank test provides the same results ( $p$-value $=0.018$; we test the hypothesis that the average number of votes/person cast for single-elimination is 1.5$)$.
} 
Table 2 reports the econometric results. While none of the regression coefficients is individually statistically significant, the overall specification is highly significant $\left(\chi_{4}^{2}=17.15, p\right.$-value $=0.002)$. Linear hypothesis tests on combinations of the coefficients indicate that profits are not significantly different from 0 among individuals in both tournament types who voted for singleelimination (Wald tests, $\chi^{2}=0.5$ and 1.55, for the single- and double-elimination tournaments, respectively, $p$-values $=0.481$ and 0.212 ). However, we reject the null hypothesis of 0 profits for those who voted for double-elimination (Wald tests, $\chi^{2}=2.98$ and 8.73 , for the single- and double-elimination tournaments, respectively, $p$-values $=0.084$ and 0.003). ${ }^{9}$

\begin{tabular}{lc}
\hline & $\begin{array}{c}(1) \\
\text { Profit }\end{array}$ \\
\hline Period & 0.034 \\
& $(0.143)$ \\
Double-Elim & -0.246 \\
& $(0.296)$ \\
Order & 0.232 \\
& $(0.414)$ \\
Voted Double-Elim & -0.355 \\
& $(0.446)$ \\
Intercept & -0.264 \\
& $(0.375)$ \\
\hline Observations & 240 \\
Wald Chi-Sq. & 17.15 \\
\hline Clustered standard errors in parentheses. \\
$* p<0.10,{ }^{* *} p<0.05, * * * p<0.01$
\end{tabular}

Table 2: GLS regression analysis of profits by tournament type in the voting treatment.Standard errors are clustered at the session level, and we include random effects for each subject to control for repeated measures.

Figures 10 and 11 display histograms of bidding behavior in each round of each tournament type in the voting treatment, and Table 3 displays summary statistics of bids by round and tournament type. The last row of the table also reports KS tests of the hypothesis that bids in matches from the endogenously chosen treatments are drawn from the same distribution as

\footnotetext{
${ }^{9}$ Further regression analysis indicated that people who bid more in round 1 in the exogenous tournaments were more likely to vote for double-elimination. As we argue in the next section, the overall pattern of behavior does not support a utility of winning explanation but perhaps these subjects just enjoy playing.
} 


\begin{tabular}{|c|c|c|c|c|c|c|c|c|}
\hline & \multicolumn{2}{|c|}{ Single-Elimination } & \multicolumn{6}{|c|}{ "Double-Elimination } \\
\hline & $\mathrm{Rd} 1$ & $\mathrm{Rd} 2$ & $\mathrm{Rd} 1$ & W.Rd2 & L.Rd2 & $\mathrm{Rd} 3$ & $\mathrm{Rd} 4$ & $\mathrm{Rd} 5$ \\
\hline Mean & 0.44 & 4.53 & 0.25 & 0.87 & 0.11 & 0.5 & 2.39 & 3.36 \\
\hline Median & {$[0.1]$} & {$[4.2]$} & {$[0.05]$} & {$[0.7]$} & {$[0]$} & {$[0.3]$} & {$[2.25]$} & [3.65] \\
\hline Std. Dev. & $(0.67)$ & $(2.85)$ & $(0.35)$ & $(0.83)$ & $(0.2)$ & $(0.61)$ & $(1.51)$ & (1.18) \\
\hline KS D-Statistic & $0.24^{* * *}$ & 0.13 & 0.17 & 0.22 & 0.10 & 0.24 & 0.10 & $0.36^{*}$ \\
\hline
\end{tabular}

Table 3: Summary statistics of bids by round and tournament type in the voting treatment.

bids in the strategically equivalent matches from the exogenous treatments. Overall, bidding behavior here is very similar to what we observed in the exogenously imposed tournaments.

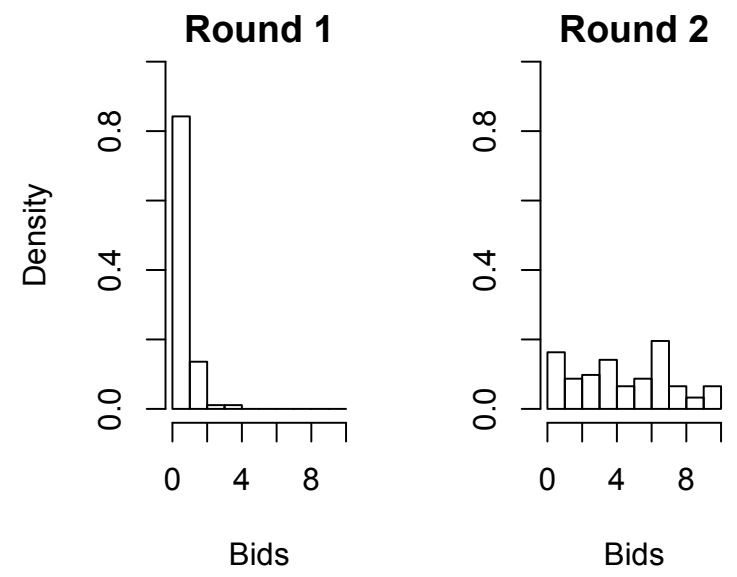

Figure 10: Histograms of bidding behavior in each round of the single-elimination tournaments in the voting treatment.
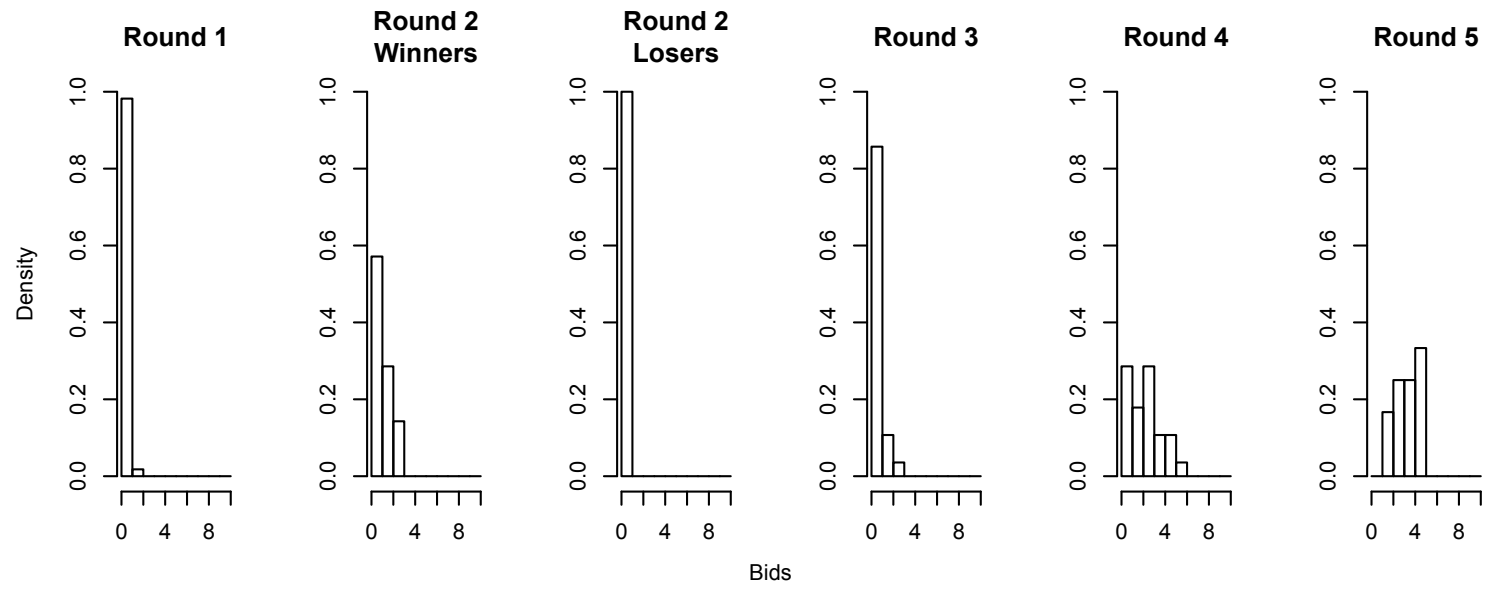

Figure 11: Histograms of bidding behavior in each round of the double-elimination tournaments in the voting treatment. 
Finding 3: Subjects reveal a preference for single-elimination tournaments. Subjects who were in the double-elimination tournament first (when it was the most costly), are more likely to vote for single-elimination, and those who vote for double-elimination tournaments earn lower profits, regardless of the tournament type implemented. Thus we reject Theoretical Hypothesis 3 in favor of Behavioral Hypothesis 3. Finally, bidding data in the Vote treatment are largely consistent with behavior when the tournament type is exogenous.

\section{Discussion}

Given that contestants do not behave in accordance with the payoff-maximizing theoretical predictions, we briefly consider various alternative explanations while noting that the experiments were not designed to distinguish among these alternative models. Thus, where the data seem to support an alternative, we view our results as suggesting the need for future work testing these explanations directly.

One possible explanation is that subjects are making errors. If the errors were completely random, then we would expect to see a uniform distribution of bids in each match, but this is clearly not what we observe. The quantal response model holds that subject errors are made in proportion to the relative payoffs of various actions. That is, actions that are nearly as good as the optimal choice are played more frequently than actions that yield substantially worse expected outcomes. This model would generate positive bids with positive probability when contestants are expected to bid zero. Further, in these matches one would observe small bids more frequently than large bids, which is observed (excluding round 4 of the double-elimination tournament). However, in the matches where bidders are expected to bid uniformly over [0, $V]$, the quantal response equilibrium would not yield different predictions (see Goeree et al. (2008) for more discussion of the QRE model), and thus this model cannot explain behavior in the winner-winner matches of round 2 in either tournament type or in round 5 matches of the double-elimination tournament.

Another possibility is that subjects simply fail to properly backwards induct. To bid zero in early rounds requires that subjects understand that all of their surplus is bid away on average 
in later rounds. If subjects do not anticipate this, then they may bid when they are not predicted to do so. A wide array of laboratory experiments have shown that people have difficulty backwards inducting. However, this failure often evaporates with experience (see Smith et al. (1988) for an example from asset pricing experiments and McCabe (1989) for an example from acceptance of fiat money in experiments). While the data from later single-elimination tournaments does begin to approximate the theoretical predictions, this is not the case for double-elimination tournaments. Even with repeated experience, subjects do not place high bids in round 5, and bidders facing elimination in round 4 do not simply give up. That is, we do not see any evidence that behavior converges to the theoretical predictions with repetition. Thus, the observed behavior does not appear to be an issue of backwards induction.

A common behavioral explanation of "overbidding" is that subjects receive a non-pecuniary utility from winning. Essentially this means that the researcher has simply underspecified the payoff from winning the prize. How such a utility of winning would affect bidding behavior in a tournament depends on whether this bonus is realized at the level of a match or at the level of the tournament.

If the utility of winning is only gained by winning the tournament, then the model in Section 2 could be adjusted by replacing $V$ with $V+U$ where $U$ denotes the utility of winning the tournament. The result would be that bidders should randomize over the larger interval $[0, V+U]$ if allowed in round 5 of the double-elimination tournament (if it is reached) and in the "winnerwinner" match of round 2 for either tournament. Bidders should still bid 0 in all other matches since expected surplus is dissipated in the matches where subjects randomize over $[0, V+U]$. There would still be no difference between tournament types. In our experiments, subjects could not bid above $V$, but this constraint should shift bids towards higher allowable amounts as compared to the uniform distribution in the final possible round of either tournament. ${ }^{10}$ However, this is not the observed pattern, as shown in the previous section. Thus, utility of winning at the tournament level does not appear to be a viable explanation.

\footnotetext{
${ }^{10}$ While one could allow subjects to bid over $V$, without prior knowledge of the value of $U$, one can never be assured that the constraint is not binding. From a practical standpoint, increasing the allowable bids also increases the endowment that subjects must be given, which in turn would reduce the number of observations that can be collected for a given budget of the researcher.
} 
If subjects gained a utility of winning at the match level, denoted $u$, then the two tournament types would lead to different total bids. In winner-winner matches of both tournaments and in round 5 of the double-elimination tournament, each bidder would randomize over [0, $V+u]$ if allowed. Again, the bid constraint placed on subjects in the experiment should lead to higher average bidding than the theory presented in section 2 , but this is not what we observed. ${ }^{11}$

An alternative explanation that seems consistent with the observed data is that people selfimpose a budget constraint as if they do not want to spend more than the total prize amount over the course of the tournament. In the single-elimination tournament, such a constraint would not be binding, and there we observe behavior that is similar to the theoretical predictions of Section 2. However, when one considers the double-elimination tournament, the concession in round 4 by the weak player is driven by the knowledge that all surplus will be bid away in round 5. However, if bidders are not willing to bid away all of the surplus because of a self-imposed constraint, then there is room for competition in round 4 , as there are positive expected profits to be had in round 5. Indeed, these are exactly the patterns that we observed (see Figure 8).

In the double-elimination tournament, one would expect that half of all subjects who end up participating in a round 5 match would spend more than the prize amount since their total bid would be the sum of two draws from $[0, V]$. In fact, only $13.6 \%$ of the time (21 cases out of 154) that a person bid in rounds 2 and $5 \mathrm{did}$ the total bid exceed $V$. Overall, only $4.4 \%$ of the time did a subject bid more than $V$ cumulatively in a double-elimination tournament (35 cases out of 800$)$. For single-elimination tournaments, it occurred $3.6 \%$ of the time (29 out of 800$)$. Figure 12 shows bids in round 5 of double-elimination tournaments as a function of the amount bid earlier in the tournament. We find a negative and marginally significant correlation between round 5 bids and the sum of bids in previous rounds (Spearman's $\rho_{n=154}=-0.15$, $p$-value $=0.07$,

\footnotetext{
${ }^{11}$ Without a constraint on bidding, in round 1 of the single-elimination tournament a bidder would randomize over $[0, u]$ since they would expect to earn 0 in the second round. In round 4 of the double elimination tournament, the player with a third round bye will receive a prize of $V+u$ from winning and expects to receive 0 from losing while the player who did not have the bye expects to receive a prize of $u$ from winning and 0 for losing. Theorem 3 in Baye et al. (1996) shows that the bidder with a bye should randomize over [0, $u]$ and has an expected profit of $V$ while the bidder who did not have the bye expects to earn 0 from the equilibrium bid, which is 0 with probability $\frac{V}{V+u}$ and randomly drawn from the interval $[0, u]$ with probability $\frac{u}{V+u}$. This implies that in round 3, bidders will randomize over $[0, u]$ and expect to earn 0 . In the winner-winner match, the loser earns 0 and the winner expects to earn $V+u$. Thus these participants should randomize over $[0, V+u]$ and expect to earn 0 . In the loser-loser match and the first round match, the winner expects to earn $u$ and the loser expects to earn 0 , and hence in these matches the contestants will randomize over $[0, u]$.
} 
two-sided test). ${ }^{12}$ Any amount previously spent is a sunk cost and should have no bearing on round 5 bidding, but this is clearly not the case.

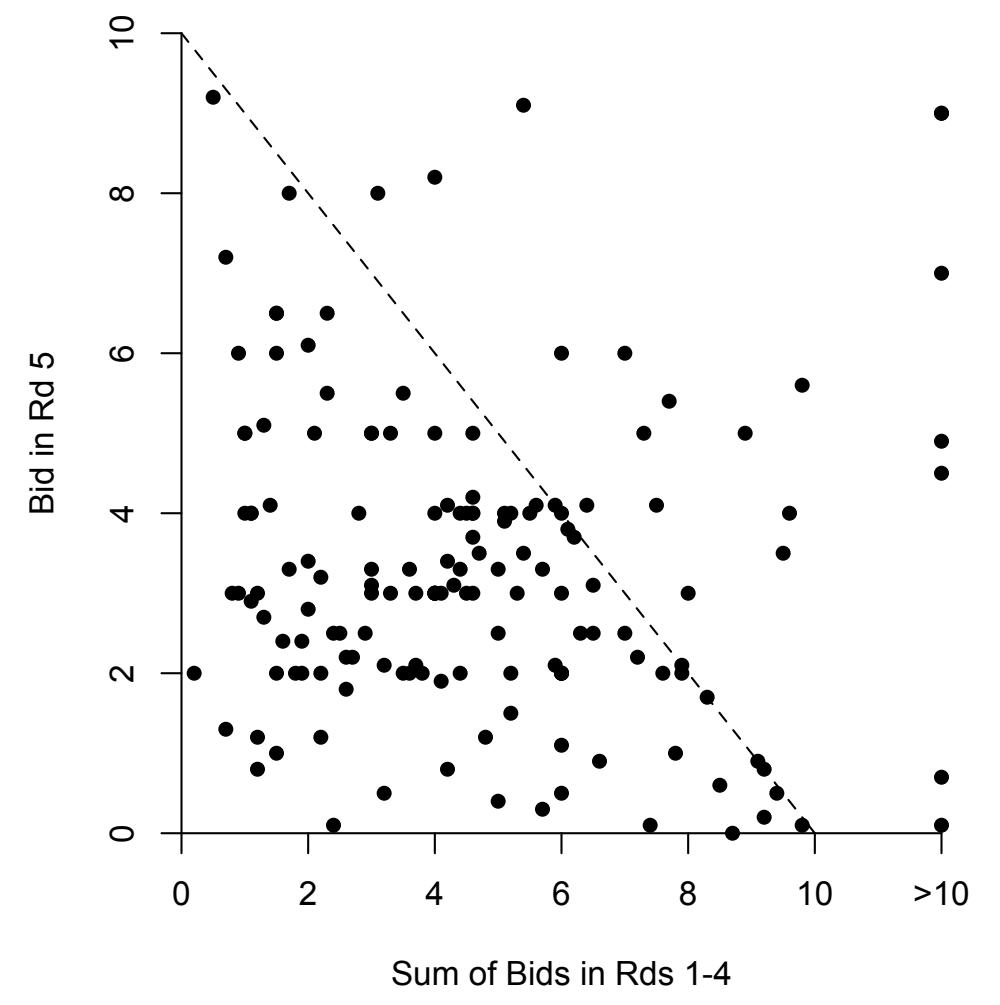

Figure 12: Scatterplot of bids in round 5 as a function of the sum of all previous bids. Points above and to the right of the dashed line constitute observations where the total sum of bids exceeded $V$. We truncate the distribution of the bid-sum from previous rounds at 10 to improve visual clarity. Seven observations with high bid-sums have been recoded and displayed as $>10$.

\section{Conclusion}

Single-elimination tournaments are relatively common in a wide variety of settings; however, double-elimination tournaments are relatively rare, being primarily used in sports. Theoretically, the two structures yield identical total investment from four contestants when each match is resolved via an all-pay auction. In single-elimination, contestants should not invest or exert effort to compete in the first round because all of the benefits of winning the tournament are expected to be competed away in the second (final) round. The double-elimination tournament involves at least twice as many matches, but theoretically most of them do not involve any real

\footnotetext{
${ }^{12}$ If we exclude the first tournament of the treatment: $\rho_{n=138}=-0.21, p$-value $=0.01$, two-sided test.
} 
competition. In fact, in equilibrium the "winner-winner" match of the second round should generate the same behavior as the final match in the single-elimination tournament and is the only match in which contestants really compete because the final (if necessary) match would not be necessary.

While the two tournament structures are theoretically equivalent, one of the most common behavioral findings for all-pay auctions and other contests is that people overbid. Given that a double-elimination tournament offers twice as many opportunities to overbid, one would expect that it would be preferred by tournament organizers if their objective is to maximize total investment. We report on a series of controlled laboratory experiments that compare behavior between these two types of tournaments. Our results show only a modest amount of overbidding and, more importantly, that total investment by contestants is indistinguishable between the two formats. Despite the similarity at the tournament level, when we look more closely at bidding behavior we find marked differences. Behavior in single-elimination tournaments is reasonably similar to the theoretical predictions. However, in double elimination tournaments, the heated competition does not occur in the second round as predicted. Instead, the competition typically occurs once the tournament is down to two contestants, in the fourth and fifth rounds. One plausible explanation is that subjects self-impose a budget constraint on their own bidding behavior so that their cumulative bid does not exceed the value of the prize, while other explanations such as a utility of winning or a failure to backwards induct do not seem consistent with the data.

The behavior we observe in the lab may offer an explanation as to why double-elimination tournaments are mostly restricted to sports. If the total investment by contestants is similar across tournaments then the choice of tournament type may come down to a matter of the cost or benefit of holding matches. In sports, the tournament organizer may generate extra-tournament profit via ticket sales and concessions whereas business plan competitions are likely to find each round costly. 


\section{References}

Altmann, S., FalK, A. and Wibral, M. (2012). Promotions and incentives: The case of multistage elimination tournaments. Journal of Labor Economics, 30 (1), 149-174.

AmAldoss, W. and RAPOPORT, A. (2009). Excessive expenditure in two-stage contests: Theory and experimental evidence. In Game Theory: Strategies, Equilibria, and Theorems., Hauppauge, NY: Nova Science Publishers.

Amegashie, J. A., CAdsby, C. B. and Song, Y. (2007). Competitive burnout: Theory and experimental evidence. Games and Economic Behavior, 59 (2), 213-239.

Anderson, L. R. and FREEBORN, B. A. (2010). Varying the intensity of competition in a multiple prize rent seeking experiment. Public Choice, 143 (1-2), 237-254.

BAIK, K. H. (1994). Effort levels in contests with two asymmetric players. Southern Economic Journal, 61 (2), 367-378.

BAYE, M., KOVENOCK, D. and VRIES, C. (1996). The all-pay auction with complete information. Economic Theory, 8 (2), 291-305.

BAye, M. R., Kovenock, D. and De VRIES, C. G. (1993). Rigging the lobbying process: an application of the all-pay auction. The American Economic Review, pp. 289-294.

DAGAEV, D. and SONIN, K. (2013). Winning by losing: Incentive incompatibility in multiple qualifiers, cEPR Discussion Papers.

DAVIS, D. D. and REILly, R. J. (1998). Do too many cooks always spoil the stew? an experimental analysis of rent-seeking and the role of a strategic buyer. Public Choice, 95 (1-2), 89-115.

Dechenaux, E., Kovenock, D. and Sheremeta, R. M. (2012). A survey of experimental research on contests, all-pay auctions and tournaments. Tech. rep., Discussion Paper, Social Science Research Center Berlin (WZB), Research Area'Markets and Politics', Research Professorship \& Project'The Future of Fiscal Federalism'.

Goeree, J. K., Holt, C. A. and Palfrey, T. R. (2008). Quantal response equilibrium. In The New Palgrave Dictionary of Economics, Palgrave Macmillan, Basingstoke.

Groh, C., Moldovanu, B., SelA, A. and Sunde, U. (2012). Optimal seedings in elimination tournaments. Economic Theory, 49 (1), 59-80.

Kimbrough, E. O., SheremetA, R. M. and ShieldS, T. (2014). When parity promotes peace: Resolving conflict between asymmetric agents. Journal of Economic Behavior E Organization, 99, 96-108.

LAZEAR, E. P. and ROSEN, S. (1981). Rank-order tournaments as optimum labor contracts. The Journal of Political Economy, 89 (5), 841-864.

MCCABE, K. A. (1989). Fiat money as a store of value in an experimental market. Journal of Economic Behavior E Organization, 12 (2), 215-231.

Moulin, H. (1986). Game theory for the social sciences. NYU Press, New York. 
PARCO, J. E., RAPOPORT, A. and Amaldoss, W. (2005). Two-stage contests with budget constraints: An experimental study. Journal of Mathematical Psychology, 49 (4), 320-338.

Potters, J., De VRies, C. G. and VAN Winden, F. (1998). An experimental examination of rational rent-seeking. European Journal of Political Economy, 14 (4), 783-800.

R Development Core TeAm (2012). R: A Language and Environment for Statistical Computing. $\mathrm{R}$ Foundation for Statistical Computing, Vienna, Austria, ISBN 3-900051-07-0.

SHEREMETA, R. M. (2010a). Expenditures and information disclosure in two-stage political contests. Journal of Conflict Resolution, 54 (5), 771-798.

- (2010b). Experimental comparison of multi-stage and one-stage contests. Games and Economic Behavior, 68 (2), 731-747.

- (2013). Overbidding and heterogeneous behavior in contest experiments. Journal of Economic Surveys, 27 (3), 491-514.

SISAK, D. (2009). Multiple-prize contests: The optimal allocation of prizes. Journal of Economic Surveys, 23 (1), 82-114.

Smith, V., SuchaneK, G. and Williams, A. (1988). Bubbles, crashes, and endogenous expectations in experimental spot asset markets. Econometrica, 56 (5), 1119-1151.

SteIN, W. E. (2002). Asymmetric rent-seeking with more than two contestants. Public Choice, $113(3-4), 325-336$. 


\section{A Instructions}

\section{GENERAL INSTRUCTIONS}

This is an experiment in the economics of strategic decision-making. You will participate in a sequence of tournaments for a money reward. Various research agencies have provided funds for this research. The instructions are simple. If you follow them closely and make appropriate decisions, you and the 7 other participants in this experiment can earn an appreciable amount of money, which will be paid to you in $\mathrm{CASH}$ at the end of today's experiment. You have already received a $\$ 20.00$ endowment (this includes the $\$ 5$ show up fee). The experiment will consist of a sequence of tournaments and at the end of the experiment we will randomly choose 1 of the tournaments for actual payment. Your final earnings will be $\$ 20.00$ + your earnings from the randomly chosen tournament (which may be positive or negative).

It is very important that you remain silent and do not look at other people's decisions. If you have any questions, or need assistance of any kind, please raise your hand and an experimenter will come to you. If you talk, laugh, exclaim out loud, etc., you will be asked to leave and you will not be paid. We expect and appreciate your cooperation. The remainder of the instructions will describe the decisions you may face in each period.

\section{EXPERIMENT DETAILS}

At the beginning of each tournament, you will be randomly and anonymously placed into a group of 4 participants and randomly assigned a color. You will retain this color and remain in this group for the duration of the tournament. However, each person will be randomly assigned a color, and the composition of your group will be changed randomly for each new tournament. We change the group composition and the colors randomly between tournaments so that you cannot identify whom you are bidding against.

In each tournament, you will compete with the other people in your group by bidding for a reward worth $\$ 10.00$. There will be a single winner who receives the reward, all other people in the group will receive no additional money. Regardless of who receives the reward, all participants will have to pay their bids. At the end of the experiment we will randomly select 1 tournament for payment. If the earnings from that tournament are negative, we will subtract them from your endowment. If the earnings are positive, we will add them to your endowment.

\section{PRACTICE GAMES}

Each tournament will consist of a series of games. In each game, you will bid against one other person. The person who submits the highest bid wins the game, BUT both people have to pay their bid, regardless of whether they win or lose the game. Ties are broken randomly by the computer. We will start with some practice games which cannot be chosen for payment. The practice games are so that you can familiarize yourself with the computer interface. After the practice games, you will read extra instructions explaining the tournaments.

Your color is listed in the middle of the screen. Find your color and then find the bid box for your color. Enter a bid for the $\$ 10.00$ reward. You may bid any amount between $\$ 0.00$ and $\$ 10.00$ in increments of $\$ 0.10$. Once both people enter a bid, the winner will be revealed and you will see your payoff in the table. When you are ready to practice, please click the button below. Are there any questions?

\section{SINGLE-ELIMINATION TOURNAMENTS}

In this part, you will compete for the $\$ 10$ reward in a series of single-elimination tournaments. Singleelimination tournaments get their name because you only have to lose one game to be eliminated. Each tournament is composed of two rounds.

In the first round, your group of 4 will be randomly divided into two pairs. You will bid against the person you are paired with for your game. You may bid any amount between $\$ 0.00$ and $\$ 10.00$. The other person has the same choice. The winner of each game is the person who bids the most with ties broken randomly. The loser will be eliminated. In the second round, the two first-round winners will compete 
with each other. If you win in the first round, you may bid any amount between $\$ 0.00$ and $\$ 10.00$ in the second round. As in the first round, the winner is the person who bids the most with ties broken randomly. The loser is eliminated.

Remember, no matter whether you win or lose, your bid(s) are subtracted from your endowment. Only the winner of the tournament receives the reward. Thus, you may receive one of three payments:

1. If you lose in the first round, you receive: $\$ 0.00$ - your bid in the first round

2. If you win in the first round and lose in the second round, you receive: $\$ 0.00$ - your bid in the first round - your bid in the second round

3. If you win in both rounds, you receive: $\$ 10.00$ - your bid in the first round - your bid in the second round

Notice that if the total amount you bid across all games in the tournament exceeds $\$ 10.00$, then you will lose money in the tournament even if you are the winner. Remember you have already received a \$20.00 endowment. In any tournament, you may receive either positive or negative earnings. At the end of the experiment we will randomly select 1 tournament for payment. If the earnings from that tournament are negative, we will subtract them from your endowment. If the earnings are positive, we will add them to your endowment. Please click the button below when you are ready to begin.

\section{DOUBLE-ELIMINATION TOURNAMENTS}

In this part, you will compete for the reward in a series of double-elimination tournaments. Doubleelimination tournaments get their name because you have to lose two games to be eliminated. Each tournament is composed of up to five rounds.

In the first round, your group of 4 will be randomly divided into two pairs. You will compete with the person you are paired with for your game. You may bid any amount between $\$ 0.00$ and $\$ 10.00$. The other person has the same choice. The winner in each game is the person who bids the most with ties broken randomly.

In the second round, the winners from the first round will compete with each other, and the losers from the first round will compete with each other. As in the first round, both people in a pair can bid any amount between $\$ 0.00$ and $\$ 10.00$. The winner in each game is the person who bids the most with ties broken randomly. After the second round, one person will be eliminated: the person who has lost twice.

In the third round, the two bidders who have each won once and lost once will compete with each other. The person who has won twice gets a "bye", meaning he/she does not have to participate in this round and automatically advances to the fourth round. The two bidders who compete in the third round can bid any amount between $\$ 0.00$ and $\$ 10.00$. The winner is the person who bids the most with ties broken randomly. The loser of round 3 is eliminated.

In the fourth round, the person with the "bye" will compete with the person who won in the third round. Again, both bidders can bid any amount between $\$ 0.00$ and $\$ 10.00$. The winner is the person who bids the most; in this round, and this round only, ties go to the person who had the "bye". Now, two things can happen:

1. If the winner from the third round is the loser in the fourth round, he/she is eliminated and the tournament is over.

2. If the winner from the third round is the winner in the fourth round, then the tournament extends to the fifth round.

Remember, each person has to lose twice to be eliminated. 
If the tournament goes to a fifth round, the two bidders from the fourth round will compete one more time. Again both bidders can bid any amount between $\$ 0.00$ and $\$ 10.00$. The winner is the person who bids the most; ties are broken randomly. The loser is eliminated.

In this tournament, no matter whether you win or lose, your bid(s) are subtracted from your endowment. Only the winner of the tournament receives the reward. To conserve space, we will use bid ${ }_{1 s t}$ to mean your bid in the first round and bid $_{2 n d}$ to mean your bid in the second round, and so on. Thus, you may receive one of six payments:

1. If you are eliminated after the second round:

$$
\$ 0.00-\text { bid }_{1 s t}-\operatorname{bid}_{2 n d}
$$

2. If you are eliminated after the third round:

$$
\$ 0.00-\operatorname{bid}_{1 s t}-\text { bid }_{2 n d}-\text { bid }_{3 r d}
$$

3. If you are eliminated after the fourth round:

$$
\$ 0.00-\text { bid }_{1 s t}-\text { bid }_{2 n d}-\text { bid }_{3 r d}-\text { bid }_{4 t h}
$$

4. If you are eliminated after the fifth round:

$$
\$ 0.00-\text { bid }_{1 s t}-\text { bid }_{2 n d}-\text { bid }_{3 r d}-\text { bid }_{4 t h}-\text { bid }_{5 t h}
$$

(note bid $_{3 r d}=0$ if you have a bye)

5. If you win in the fourth round:

$$
\$ 10.00-\operatorname{bid}_{1 s t}-\operatorname{bid}_{2 n d}-\operatorname{bid}_{4 t h}
$$

6. If you win in the fifth round:

$$
\begin{aligned}
& \$ 10.00-\text { bid }_{1 s t}-\text { bid }_{2 n d}-\text { bid }_{3 r d}-\text { bid }_{4 t h}-\text { bid }_{5 t h} \\
& (\text { note bid } \\
& 3 r d
\end{aligned}
$$

Notice that if the total amount you bid across all games in the tournament exceeds $\$ 10.00$, then you will lose money in the tournament even if you are the winner. Remember you have already received a \$20.00 endowment. In any tournament, you may receive either positive or negative earnings. At the end of the experiment we will randomly select 1 tournament for payment. If the earnings from that tournament are negative, we will subtract them from your endowment. If the earnings are positive, we will add them to your endowment. Please click the button below when you are ready to begin.

\section{VOTE FOR YOUR TOURNAMENT CHOICE}

Now, you will participate in a series of tournaments where you will vote to decide which type of tournament to enter. Before each tournament, each of the 8 people in this experiment will see two buttons labeled "Single Elimination" and "Double Elimination". Please click on one button to vote for your preferred tournament type. The majority vote will determine the tournament type. Ties will be broken randomly. Please click the button below when you are ready to begin.

\section{B Additional Tables and Figures}

This appendix provides additional analysis of subject behavior.

\section{B.1 Profits}

In Table B1 we report analysis on profit. Specifically, we regress individual profits on an intercept, a time trend variable within a treatment (Period), a dummy indicating if it was the first treatment the subject observed (First Half), and double-elimination treatment dummy (Double-Elim). We also report a second 
specification that controls for sex (Male). To control for the repeated observations from the same subject we include random effects at the subject level, and we cluster standard errors at the session level.

In both regressions, negative and significant coefficients on the intercept indicate that bidders earn negative profits on average, while positive and significant coefficients on Period suggest that profits become less negative with experience. The negative and significant coefficient on First Half indicates that bidders tend to overdissipate the prize to a larger degree in the first treatment they participate in, regardless of the tournament type. With respect to sex, the results indicate that males earn higher profits in single- but not double-elimination tournaments.

\begin{tabular}{lcc}
\hline & $(1)$ & $(2)$ \\
& Profit & Profit \\
\hline Period & $0.157^{* *}$ & $0.163^{* * *}$ \\
& $(0.064)$ & $(0.062)$ \\
Double-Elim & -0.448 & -0.176 \\
& $(0.327)$ & $(0.388)$ \\
First Half & $-0.641^{* *}$ & $-0.699^{* *}$ \\
& $(0.327)$ & $(0.303)$ \\
Male & & $0.419^{*}$ \\
& & $(0.232)$ \\
Double-Elim $\times$ Male & & -0.400 \\
& & $(0.625)$ \\
Intercept & $-1.328^{* * *}$ & $-1.614^{* * *}$ \\
& $(0.454)$ & $(0.418)$ \\
\hline Observations & 1600 & 1600 \\
Wald Chi-Sq. & 13.59 & 50.71 \\
\hline
\end{tabular}

Standard errors in parentheses.

${ }^{*} p<0.10,{ }^{* *} p<0.05,{ }^{* * *} p<0.01$

Table B1: GLS Regression Analysis of Individual Profits, All Treatments. Column 1 shows the effects of treatment status, period, and treatment order on profits. Column 2 includes a gender dummy and a gender $\times$ treatment interaction. The regressions include random effects for each subject to control for repeated observations, and the standard errors are clustered at the session level.

\section{B.2 Bidding}

As an alternative method of testing the bid predictions of the theory, we regress individual bids on an intercept, Period, First Half, Double-Elim, tournament round dummies (Round 2, Round 3, Round 4, and Round 5), Double-Elim $\times$ Round 2, a dummy for the "winner-winner" match (Winner-Winner) and DoubleElim $\times$ Period $\times$ First Half interactions. Since bids are censored above and below (at $\$ 0$ and $\$ 10$ ), we estimate this regression using a Tobit model and we use bootstrapping to cluster standard errors at the subject level. Table B2 reports the results.

The intercept captures bids in round 1 of single-elimination tournaments. A positive and significant coefficient indicates that these bids are significantly different from zero ( $p$-value $<0.01$ ), but a Wald test indicates that round 1 bids in the double-elimination tournaments are not significantly different from zero ( $p$-value $=0.43)$. In what follows, we report Wald tests of the hypothesis that the relevant coefficients sum to 0 . For round 2 "loser-loser" matches, $p$-value $=0.45$; for round 3 matches, $p$-value $<0.001$; for round 4 matches, $p$-value $<0.001$. In general, regression analysis is consistent with the analysis reported above. Similarly, testing only those matches in which bids are expected to be equal to 5 on average (i.e. round 2 "winner-winner" matches and round 5), Wald tests reject the null hypothesis that the relevant coefficients 
sum to 5 (all $p$-values $<0.001$ ). We also present a second specification that controls for sex (see B2). The results suggest that men and women bid similarly.

\begin{tabular}{|c|c|c|}
\hline & $\begin{array}{l}(1) \\
\text { Bid }\end{array}$ & $\begin{array}{l}(2) \\
\text { Bid }\end{array}$ \\
\hline Double-Elim & $\begin{array}{c}-0.788^{* * *} \\
(0.175)\end{array}$ & $\begin{array}{c}-0.972^{* * *} \\
(0.209)\end{array}$ \\
\hline Round 2 & $\begin{array}{c}2.030^{* * *} \\
(0.293)\end{array}$ & $\begin{array}{c}2.035^{* * *} \\
(0.243)\end{array}$ \\
\hline Round 3 & $\begin{array}{c}0.671^{* * *} \\
(0.091)\end{array}$ & $\begin{array}{c}0.672^{* * *} \\
(0.094)\end{array}$ \\
\hline Round 4 & $\begin{array}{c}2.072^{* * *} \\
(0.187)\end{array}$ & $\begin{array}{c}2.072^{* * *} \\
(0.195)\end{array}$ \\
\hline Round 5 & $\begin{array}{c}2.847^{* * *} \\
(0.248)\end{array}$ & $\begin{array}{c}2.853^{* * *} \\
(0.263)\end{array}$ \\
\hline Double-Elim $\times$ Round 2 & $\begin{array}{c}-2.342^{* * *} \\
(0.290)\end{array}$ & $\begin{array}{c}-2.345^{* * *} \\
(0.226)\end{array}$ \\
\hline Period & $\begin{array}{c}-0.097^{* * *} \\
(0.022)\end{array}$ & $\begin{array}{c}-0.097^{* * *} \\
(0.020)\end{array}$ \\
\hline First Half & $\begin{array}{c}0.468^{* * *} \\
(0.139)\end{array}$ & $\begin{array}{c}0.480^{* * *} \\
(0.158)\end{array}$ \\
\hline Winner-Winner & $\begin{array}{c}1.001^{* * *} \\
(0.106)\end{array}$ & $\begin{array}{c}0.997^{* * *} \\
(0.133)\end{array}$ \\
\hline Male & & $\begin{array}{c}-0.168 \\
(0.183)\end{array}$ \\
\hline Double-Elim $\times$ Male & & $\begin{array}{c}0.289 \\
(0.224)\end{array}$ \\
\hline Intercept & $\begin{array}{c}0.939^{* * *} \\
(0.230)\end{array}$ & $\begin{array}{c}1.044^{* * *} \\
(0.251)\end{array}$ \\
\hline Observations & 3754 & 3754 \\
\hline Wald Chi-Sq & 424.2 & 532.6 \\
\hline
\end{tabular}

Table B2: Tobit Regression Analysis of Bids, By Round and Treatment. The regressions include random effects for each subject to control for repeated observations and bootstrapped standard errors. 